\title{
Towards a Critically Conscious Approach to Social and Emotional Learning in Urban Alternative Education: School Staff Members' Perspectives
}

\section{Christopher D. Slaten}

Department of Educational, School, Counseling Psychology, University of Missouri

\section{Decoteau J. Irby}

Department of Educational Policy Studies, University of Illinois at Chicago

\section{Kevin Tate}

Department of Counselor Education, Marquette University

\section{Roberto Rivera}

Department of Educational Psychology, University of Illinois at Chicago.

\begin{abstract}
Social and emotional learning (SEL) has been well researched and validated as an important component of youth education (Durlak, Weissberg, Dymnicki, Taylor, \& Schellinger, 2011; Elias et. al., 1997). However, much of the literature implies a very monolithic approach to SEL interventions (Watts, Griffith, \& Abdul-Adil, 1999). The current study examines a predominately African-American urban alternative school's unique approach to reaching students' SEL needs. Utilizing Consensual Qualitative Research (Hill, 2012), researchers interviewed 15 staff members at the school, ranging from teachers to mental health professionals to community educators, to obtain a thorough understanding of the unique approaches to SEL within urban alternative education. Implications for educators and mental health professionals working in alternative educational settings are discussed.
\end{abstract}

Keywords: critical consciousness, social and emotional learning, alternative education, consensual qualitative research, at-risk youth 
In the United States today, 5.8 million youth are neither in school nor working (Lewis \& BurdSharps, 2010). If they do not obtain a high school diploma, these youth will earn $\$ 200,000$ less than a high school graduate over their lifetime and almost a million dollars less than a college graduate (National Center for Educational Statistics, 2011). Not only is this a significant concern for the future of these youth, but also for the future of society as a whole. The estimated economic cost of youth that lack this connection to school or work is approximately $\$ 97.3$ billion dollars in taxes and governmental support (Lewis \& Burd-Sharps, 2010). Across the nation, the American educational system continues to struggle to resolve the challenge of keeping students who are at risk for academic failure in school. These students are disproportionately impoverished persons of color, victims of bullying, those experiencing family turmoil, and youth with mental health concerns (Price, Pepper, \& Brocato, 2006). This is a critical issue for schoolbased mental health and many continue to advocate for more services addressing the social and emotional needs of students (Clark \& Breman, 2009; Kress \& Elias, 2006; Ross, Powell, \& Elias, 2002; Tolan \& Dodge, 2005).

In an effort to combat school attrition, alternative education has emerged as a means to educate students who are not being accommodated by traditional schools. For many years, alternatives for educating youth who have been ostracized by the educational system have been employed, including schools with a non-traditional focus (e.g., fine arts schools, trade schools, charter schools) and alternative schools that group students for convenience in administration and instruction (Cable, Plucker, \& Spradlin, 2009; Kim \& Taylor, 2008; Oakes, 2005). According to the National Center for Education Statistics (NCES, 2011), in the United States alone there are over 12,000 alternative schools serving more than 600,000 students. Within these schools are a disproportionate number of students at risk because of poverty, peer victimization, family turmoil, and mental health concerns (Price, Pepper, \& Brocato, 2006). Therefore, students in these settings have arguably the highest need for social and emotional learning (SEL), but these schools typically have few resources to address these needs. Although several studies have informed us about alternative education settings, more research is needed to understand the SEL that occurs within these settings.

\section{Alternative Education}

Alternative schools are broadly defined as specialized educational programs that function outside of traditional schools. Early scholars studying the effects of alternative schools (Raywid, 1981, 1983) further distinguished the alternative settings, arguing that to qualify as alternative: the educational program must not require students and families to bear additional costs; must be available to all students within a given district; must have administrative autonomy; and, must be voluntary. These important distinctions differentiated alternative schools from special education programs and mandated placements for adjudicated youth. In more recent scholarship, alternative schools and education refer almost without exception to educational programs for students at risk of failing from traditional schools due to truancy, pregnancy, learning challenges, and/or behavioral problems. These schools take the form of high school programs, community schools for suspended and expelled students, and state detention facilities (Guerin \& Denti, 1999). 
Foley and Pang (2006) described three frameworks that shape the curriculum and structure of alternative schools. Type I schools are voluntary-choice schools that offer alternative curriculum themes (e.g., STEM, creative arts) and instructional approaches (e.g., experiential learning, project-based learning). Type II programs are "last chance" opportunities for students deemed disruptive in traditional school environments with attendance often being mandated by administration. These settings typically carry a strong behavior-modification emphasis but differ little from traditional schools in curriculum innovation and pedagogical offerings. Type III programs emphasize remediation and rehabilitation. All of these programs work toward preparing students to re-enter traditional school settings successfully. Although alternative programs operate according to several possible models, programs are typically characterized by student enrollments of less than 200, low student-teacher ratios, individualized and self-paced instruction, and less formal classroom structure. These characteristics enable teachers to individualize instruction to meet students' specific academic and SEL needs (Cox, 1999; Foley \& Pang, 2006; Franklin, Skeeter, Kim, \& Tripoti, 2007). Some also cite community participation and responsiveness as an additional commonality (Cox, 1999).

Although alternative education programs are intended to prevent school failure among students identified as at-risk for not completing school, alternative schools often are viewed as "dumping grounds" where troubled youth can be sent to reduce disruptions in traditional public schools (Kim \& Taylor, 2008). Administrators in urban school districts have relied on alternative schools to provide individualized educational options to youth who are unsuccessful in traditional schools. Cox (1999) found that "school officials tended to be more concerned with getting troubled students out of their schools than selecting students who may have benefitted from an alternative school experience" (p. 325). Although practitioners tout the importance of alternative schools for removing disruptive students without expelling them to the streets, others point to positive, albeit often short-term, effects of alternative schools on troubled youths' educational experiences and district-wide performance (Cox, 1999; Gut \& McGlaughlin, 2012; Reisler \& Friedman, 1978; Reilly, Reilly, \& West, 1982).

Whether alternative schools benefit the students they serve continues to be debated, complicated by the numerous school models that operate as alternative education. Research studies point to varied outcomes for faith-based programs (Sinha, 2007), twilight programs (D'Angelo \& Zemanick, 2009), mandatory disciplinary day schools for expelled students (Kennedy-Lewis, 2012), and daytime detention programs for "potentially delinquent" youth. However, because the structures, referral-placement-retention policies, and goals of alternative schools vary greatly, making generalizations about the effectiveness of alternative schools is problematic.

Critics of alternative schools tend to focus on the ways alternative education reproduces inequality related to race, class, gender, and disability. Foley and Pang's (2006) survey study of Illinois alternative school directors and principals suggested that alternative schools serve a broad range of students, a majority of whom are White. However, the fact that White students comprise a majority of alternative school students does not negate the fact that students of color are disproportionately represented in such schools. Racial minorities, students from lowincome families, and teen mothers are disproportionately placed into alternative education programs (Geronimo, 2011). Dunbar (2001; 2002) noted that alternative schools are racialized educational institutions that stigmatize the students who attend them. 
Researchers of individual alternative school settings have demonstrated that involuntary alternative disciplinary placements can further alienate students from an academics-focused curriculum that prepares them for post-secondary education or work opportunities (KennedyLewis, 2012). Students placed involuntarily into alternative school settings are more likely to be subjected to banal and simplified curriculum, and peer and adult social interactions that move them toward lives of containment and social control (Dunbar, 2001; Geronimo, 2011). Framed in this light, alternative school settings constitute an institutional linkage that bolsters school-toprison pipelines in an era dominated by zero-tolerance and removal disciplinary policies and philosophy (Geronimo, 2011; Irby, 2013; Kennedy-Lewis, 2012). By extension, alternative disciplinary placements have the potential to marginalize society's most vulnerable youth further.

Proponents of alternative schools argue that the inflexible "one size fits all" model of traditional public schools further marginalizes students who are already at risk for not completing school (D'Angelo \& Zemanick, 2009). While several scholars offer pointed and legitimate critiques of alternative school settings, highlighting the legal (Geronimo, 2011), policy (Irby, 2013), and cultural (Dunbar, 2001) structures adopted to maintain a status quo of student marginalization, proponents focus on what constitutes successful alternative school programs for students at risk of failure. Many authors draw from qualitative data collected directly from students to critique traditional schools and provide evidence that students perceive alternative settings as more conducive to their academic and socio-emotional development (Lugana-Riordan et al., 2011; Sinha, 2007).

Best practices in alternative schools often are not possible in traditional school settings or are shunned by school leaders and teachers. Some of these practices include non-traditional and flexible school hours, flexible rules and consequences, a faith-based or spiritual element, a strong home-school connection, a focus on relationships and positive school climate, and adoption of a strength-based approach with students who are often viewed from a deficitorientation in the traditional school setting. Researchers who investigate "what works" usually focus their inquiry on individual settings (D'Angelo \& Zemanick, 2009; Franklin et al., 2007; Sinha, 2007) or a small number of alternative programs (Quinn, Poirier, Faller, Gable, \& Tonelson, 2006), seeking to discover and illuminate common program aspects that foster positive educational and social experiences for youth that traditional schools do not serve well.

\section{Social Emotional Learning (SEL)}

Many students attending alternative schools are vulnerable to a variety of social and emotional risk factors such as low socioeconomic status, family difficulties, and physical and emotional trauma (Flower, McDaniel, \& Jolivette, 2011; Guerin \& Denti, 1999). As researchers, educators, and policy makers attempt to devise interventions to assist these youth both academically and psychologically, few solutions have emerged. Social-emotional learning (SEL) was developed to educate and assist youth with skill acquisition and support related to emotional regulation and positive relationships (Weissburg, 2000). Considerable research has suggested that SEL has an impact on youth (Durlak, Weissberg, Dymnicki, Taylor, \& Schellinger, 2012). Durlak et al. (2012) conducted a meta-analysis examining 213 studies of intervention outcome research and concluded that SEL instruction demonstrated better academic performance, improved attitudes and behaviors, fewer negative behaviors, and reduced emotional distress. 
Although SEL researchers have demonstrated its efficacy in multiple domains, many states and school districts still refrain from making SEL a consistent commitment. Further, some scholars are concerned that SEL interventions are not sufficiently differentiated to address varying needs during implementation (Castro-Olivo, 2010). This mentality is limited, most importantly because concerns are unique and need contextualized interventions and learning accordingly (CastroOlivo \& Merrell, 2012). Youth in alternative school settings often have unique experiences and have more exposure to traumatic home and school lives (Flower et al., 2011). There has been little discussion in the SEL domain about youth who find themselves in these contextual circumstances. Further, youth in urban communities have different experiences than those in rural or suburban communities. This environmental difference is not acknowledged in the current SEL literature (Castro-Olivo \& Merrell, 2012). The current research examines the approach to SEL in one urban alternative school working with marginalized youth at risk for academic failure. The goal of this study was to understand this unique educational approach through the voices of the school professionals working there and to understand the utilization of SEL with youth in this specific context.

\section{Methods}

We employed Consensual Qualitative Research (CQR; Hill, 2012; Hill, Thompson, \& Williams, 1997) as our method for gathering and analyzing data. This form of qualitative research was utilized specifically because of the exploratory nature of the research questions and the requirement to quantify themes, making the results more palatable to a broader audience (Hill, 2012). CQR is an inductive qualitative approach that utilizes open-ended questions to stimulate participant thinking, while studying a small number of cases in-depth (i.e., 8 to 15 participants; Hill, 2012). One of the greatest strength of the CQR approach is the reliance on multiple perspectives, including at least three research team members conducting the data analysis and one auditor checking the work of the primary team. This method has been used primarily in the counseling field, but has also been utilized in educational contexts to examine phenomena such as teachers' perceptions of reform implementation (e.g., Greenfield, Rinaldi, Proctor, \& Cardarelli, 2010), youth perception of parental acceptance based on their sexual minority status (Samarova, Shilo, \& Diamond, 2013), and understanding the future goals of Latino adolescents in an immigrant community (Gonzalez, Stein, Shannonhouse, \& Prinstein, 2012). CQR allows researchers to conduct a systematic qualitative analysis of a phenomenon. In this case, the focus was on an alternative school integrating SEL into the school culture from the perspective of those implementing it.

\section{Setting}

The context for the study was an alternative school (Type III) in a large urban public school district in the upper Midwest within a city with a population of over 600,000 . The school functioned primarily as an opportunity for credit recovery through on-line learning. Students worked both at school and at home, acquiring high school credits. The goal of the school was to transition students from recovering academic credits back to a traditional setting. Educators at the school reported that they attempted to accomplish this in non-traditional ways, placing an emphasis on nurturing and supporting students social, emotional, and cultural needs. Most students came to the school building for a half-day and were provided with the necessary tools to work from home for the remainder of the school day. The first author had previously visited 
the school and had conversations with administrators about their innovative educational approach. The school had a vested interest in the research project as an opportunity for them to advocate for their unique school setting and illuminate their approach to alternative education.

At the time of data collection the school was serving approximately 175 students, although enrollment numbers fluctuated daily as a result of frequent student relocation. Student enrollment had traditionally been almost entirely African-American (99\% African-American, 1\% Latino), and fairly evenly divided between males and females (55\% female; $45 \%$ male). Approximately $80 \%$ of the enrolled students were eligible for free or reduced lunch cost. In addition, the vast majority of students had previously had difficulty in traditional educational contexts manifested in many ways: adjudication (approximately $30 \%$ of the school population with mostly armed robbery and/or burglary charges), expulsion from other schools, previously dropping out of school, truancy issues, and discomfort socially or academically in a large traditional school setting.

\section{Participants}

All staff at the school, 23 professional staff members, were invited to participate in the study, and 15 chose to participate: three administrators, four teachers, a school psychologist, a social worker, a special education teacher, a school counselor, and four community educators contracted from the community. This diversity of participants' responsibilities within the school allowed for exploration of the target phenomenon from multiple perspectives. The interviews were conducted within the school building and were 40 to 60 minutes in duration with one interview per participant. Demographically, $80 \%$ of participants identified themselves as AfricanAmerican (12 African-American, 3 White), 67\% identified as male (10 male, 5 female), and participant ages ranged from 31 to 55 .

\section{Procedure}

The main research team included a White counseling psychology male faculty member who has utilized CQR in multiple studies, an African-American male educational leadership faculty member, one Middle-Eastern male educational leadership graduate student, and one Latino male educational psychology graduate student.. An additional counselor education faculty member, familiar with CQR, served as an auditor for triangulation during analysis. The first author trained the other research team members in the utilization of CQR following the suggestions of Hill (2012): providing literature on the CQR process, having discussions on these readings, practicing coding together as a research team, and the first author made himself available for consultation throughout the training/research process. The research team developed questions surrounding the staff experience in working with marginalized youth and addressing their academic concerns and their social/emotional needs as well.

Data were collected from participants using a semi-structured interview format. CQR methodology requires a consistent set of questions across participants, but allows for each interviewer to ask unique follow-up questions that deepen understanding of the target phenomena (Hill, 2012). An initial interview protocol was developed based on existing literature. Two outside researchers familiar with qualitative research reviewed the protocol and minor revisions were made based on feedback. The final interview protocol was comprised of nine 
questions (see Appendix A) and was designed to collect data about participants' roles in the school; their perception of the school's composition and atmosphere; their perceptions of the school's approach to education and addressing unique student needs; their perceptions of how to engage students who are typically disengaged from traditional schools; and unique challenges faced by this school.

\section{Analysis}

The audio recordings of the interviews were transcribed verbatim except for minimal encouragers or stutters. Additionally, information that would identify particular individuals was omitted from the transcripts, and each individual transcript was tracked using an anonymous identifier code. To begin the analysis process, an initial list of domains (i.e., list of overarching themes or topic areas; Hill, 2012) was created from a thorough reading of the transcripts. Each individual member of the research team independently generated a list of domains from reading through the transcript of the first participant. The research team then gathered as a group to compare lists and come to consensus. The next step was to independently code another transcribed participant interview utilizing the initial domain list generated from the first transcribed interview, then the research team gathered again to compare and come to consensus. When new information suggested additional domains, they were added to the overall list and team members recoded previous interviews to accommodate the new domains. The domain list was amended as needed until there was consistency across participants after five interviews. The team then separated into dyads to code the remainder of the interviews utilizing the confirmed domain list.

Once all data were placed into one of the domains, core ideas were created for each section of data. Core ideas are identified as "phrases, thought units, sentences, and paragraphs that cover the same topic area" (Thompson, Vivino, \& Hill, 2012, p. 106). Core ideas are a more concise and conceptually clear paraphrase of what is contained in each section of data. In order to construct these core ideas for each transcript, each team member read all of the data removed from the transcripts and compiled into domains and then came to consensus about the core ideas that represented each section of data. At this stage, all transcripts, domains, and core ideas were sent to an external auditor, not a member of the analysis team, for review and feedback (Hill, 2012). The purpose of using an auditor at this stage of analysis is to increase the trustworthiness of the final results. The auditor read all of the data and the research team's analysis and suggested revisions or changes based on an outside perspective. The primary research team discussed the feedback, and made appropriate revisions.

The final step in CQR analysis is cross analysis, during which domains and core ideas from all transcripts are analyzed for categories that occur within each domain across participants. According to Hill (2012), categories are a series of subthemes/subdomains that help capture the majority of the content in a particular domain. Each team member read the core ideas within each domain and created a list of possible categories. The team then came to consensus about a final categorization scheme. Again, the results of the cross-analysis were sent to the same external auditor for review, and feedback from the auditor was incorporated where appropriate. An analysis was then conducted to determine which domains and categories were general (consisting of data from all participants), typical (consisting of data from at least half of participants), or variant (consisting of data from at least two, but less than half of participants). 


\section{Trustworthiness}

Consistent with qualitative inquiry, the author(s) spent time discussing their biases and preconceived notions regarding the direction of the results of the study (Guba, 1981). This involved extensive discussions between research team members regarding their a priori biases and the impact of their previous experiences and personal opinions throughout the analytic process. Specifically, the research team discussed their interest in advocating for underrepresented minorities (URMs) who have been marginalized by the traditional educational system.

In addition to bracketing research biases, CQR requires additional measures to ensure data trustworthiness (Hill, 2012). First, the use of group consensus "serves as a means of triangulating researchers' understanding of the data, thus contributing to the credibility of the results" (Hill, 2012, p. 11). Second, the use of an external auditor provides an analytical perspective outside of the research team and serves as an additional method. In addition, through the quantification of domains and categories the research team was able to ascertain the theoretical saturation of the data and determine that the information gathered was sufficient to answer the research questions. Together, these sources of quality assurance increase the overall trustworthiness of the final analysis, consistent with best qualitative research practices (Creswell, 2012).

\section{Results}

After analyzing the participant transcripts, the research team found that the school adopted and implemented a unique and culturally relevant approach to addressing students' social-emotional needs through critically conscious endeavors. This approach helped the school achieve its mission of helping students recover credits so that they could return to the traditional school setting. The analysis of participant transcripts resulted in four overarching domains or themes: (a) Pedagogy, (b) Relationships, (c) Community-based Model, and (d) School Environment. These domains were the modalities by which school professionals and members of the community engaged the youth in the school socially, emotionally, and academically.

\section{Domain 1: Pedagogy}

A consistent overarching theme in participants' discussion of their approach to alternative urban alternative education was tailoring the curriculum and pedagogy to the needs of the youth at the school. This differentiation was done in a multitude of ways and was discussed at length by staff members: social-emotional learning, personalized learning, cultural-relevance to youth, social/political content, and Black/African-centered content.

Social-emotional learning. Participants discussed ways the school made a concerted effort to bring attention to the social and emotional needs of the youth and help them learn how to cope effectively and process experiences throughout their lives. The school social worker discussed a group offered to young women as part of the school day,

Our girls' group, we talk about being a female in [local city], you know, and the struggles that we have as the young ladies or as women in [local city] and how we can overcome some of those struggles. 
Personalized learning. Many participants discussed the importance of making each student's educational experience productive by individualizing their learning. Participants mentioned that one way this is accomplished is through an online system that allows student and staff flexibility. A teacher offered his perspective:

So, I think that the way the curriculum is set up and I'm, it's free for us to be able to do a lot of [social-emotional learning] that because everything is already taken care of with the online component of it, you know.

Participants discussed the importance of allowing students to articulate their educational and emotional needs to staff and of the staff attempting to accommodate the youth. A school counselor said, "When the students and staff come together at a talking circle, everybody's voice is equally important, everybody's opinion is equally valued. No one person's opinion is better that the others."

Some participants discussed students' opportunities to learn experientially outside of school. One teacher mentioned a few: "So, like we'll go to youth hip-hop conferences, stuff at [local university], you know, stuff like that. We'll take them to outside things also and do stuff."

Cultural relevance to youth. Participants discussed how the school was focused on utilizing what was current and relevant to youth in urban communities in order to engage them. One community partner discussed using music and art in their work with the students:

As far as hands-on activities, sometime we have done music projects where, for instance, we get one person who is the artist and everyone else has to be like the team around that person.

Social/political content. A term frequently utilized by staff members was "restoration of consciousness," reflecting a concept similar to Paulo Freire's (1970) critical consciousness. The focus is on raising students' awareness of ways society may be placing them in a one-down position, with impact on their ability to overcome social, emotional, or academic barriers that stem from poverty, racism, and oppression. One staff member discussed how this concept is part of the school's culture:

You're not alone, you're not off by yourself. It's not a teenage thing, it's not a youth thing. It's, you know, we all face this stuff together. That is something that, that the principal really wanted to, to institute in the school from the very beginning that that had to be a part of it. This awareness, this awakening of seeing the world as it really is and then, and then facing it confidently and courageously. That, I think, is kind of unique compared to the other schools.

African-American centered content. Staff members discussed the importance of integrating culture and racial identity into discussions at the school. Specifically, participants discussed the importance of what it means to be African-American or Black. The majority of the students identify themselves as such, as is apparent here: 
So from a historical perspective uh, we, we allow that to be our lens. To, um, as a focus point I was just saying for, um, bringing across uh, a curriculum. So, um, in history, science, math, uh, examples are given that are culturally relevant to our kids. And so that they see themselves in the experience and it's not always an outside. You know, uh, or, Euro-centric perspective that um, traditional schools are, are giving. You know, if you look at textbooks and so on and so forth, it's always, um, most times based on the Euro-centric point of view.

\section{Domain 2: Relationships}

Another consistent theme that emerged was the importance of having a relationship with students and how the relationship helps to assist them both personally and educationally. Specifically, participants mentioned several ways in which this occurs: being vulnerable with students, encouraging students, knowing students personally, and believing that relationships are a pre-requisite to learning.

Being vulnerable with students. Similar to a subdomain mentioned under staff selfdiscovery, participants mentioned the importance of self-disclosure, but in this case disclosure was related to fostering stronger relationships with students. Many participants discussed the importance of sharing their own struggles and triumphs and relating those to the students' experiences.

Encouraging students. Participants emphasized the importance of encouraging students and recognizing their strengths. They mentioned that with encouragement and the recognition of their strengths then students are more likely to engage with, respect, and learn from the staff. A school administrator gave this perspective:

So, if you were this young person that had all these fights and disruptive and all that. I'm not saying that that's what you are. I'm saying that I see clearly that that's what you've done, that's not necessarily what you, what you are or what you can be. I'm interested in helping to engage you in a transformational type of experience.

Knowing students outside of school. Staff members discussed how attempting to understand youth in school through their contextual experiences outside of school fosters a strong bond between students and staff. A community partner gave an example of this bond:

So you got, uh, where they're coming from families where there's not two parents. One of the parents might be really messed up, abusive situations. So, they're bringing in kind of this mistrust of adults. And so that's, the what, they're coming, walking in this door with this mistrust of looking around going, "Ok, how are you going to use me or how are you going to use me or how are you going to mistreat me," because when they leave here, that's what they see is basically mistreatment, where it's dysfunctional adults out there that mistreat them or they look at the police, other adults who are only out to get them.

Relational needs as a pre-requisite to learning. When asked about relationships between students and staff, several participants mentioned the importance of relating to students prior to being able to help them learn. After describing student-staff relationships, a teacher said, "I 
think this is most essential because they do want to share, they want to get that out and it, it keeps them from being able to work, I think."

\section{Domain 3: Community-based Model}

A majority of the staff interviewed discussed the importance of community partners engaging youth in the school through a variety of opportunities. Several themes emerged in their responses: opportunity for emotional healing, community as a resource, and professional development.

Opportunity for emotional healing. One of the most important contributions of the community partnerships that staff members discussed was emotional healing as an outcome. Staff reported that youth frequently had an opportunity to experience healing from past emotional wounds through conversations with community members with whom they could relate. One community partner discussed his and the school's role in providing emotional support and healing:

Like, I may touch on stuff that's real deep or deeper issues. Then they'll find another community person that's able to touch on something that's a little lighter...If you're a writer, you know they're kinda pulling out all those things that may have been suppressed, didn't even know was there.

Interviewees said that many community partnerships involved individuals who had experiences similar to those of the school youth. Sharing this information with the student increased the respect and engagement of the students. One participant shared:

these are our individuals who, um, have similar experiences or have had experiences that are consistent with the experiences that our children are confronted with on a daily basis. Right? Like now. And so they're able to provide this, um, this, this, this first-hand experiential support to these kids. Um, so, I mean, it's invaluable what they actually bring to the table.

Community as a resource. Participants discussed how valuable the community surrounding the school was as a resource for students and staff. One administrator talked about community organizations that helped to support students,

I think even the fact that they give. They don't provide transportation, but they give them bus tickets every day. Um, they're just...the social workers are even just...kids that have babies. You know, they'll take them to their appointments at welfare and they'll go above and beyond.

Professional development. Not only did participants discuss the opportunities students have to engage with community partnerships, but the staff members also had opportunities to receive training and other professional development from members of the surrounding community. For example, one participant mentioned that "two professors from [University] came and talked about racial identity." 


\section{Domain 4: School Environment}

All participants discussed the impact that the school climate and culture had on student retention and engagement in activities related to academics. Several categories emerged as salient features of this discussion: climate of respect, emotional intelligence, and school vision and leadership.

Climate of respect. All participants discussed the importance of the school being a community in which students and staff members were respected and students felt they could communicate candidly with staff. One administrator discussed this culture of respect:

You know, I always start out with respect. I'm saying this environment is built off of respect. And, and I think once you start talking like that, I think the kids understand that 'cause I'm giving them, you know, autonomy.

Emotional intelligence. Staff members discussed their awareness of the need for emotional healing for youth. They mentioned the importance of helping youth process wounds and hurts from past relationships in order for them to be able to focus on their academic work. A school psychologist explained this awareness as follows:

We like to consider where we are in this building-liberated space, right? And what we mean by liberated space is we try to provide an environment here that is open, free, honest and supportive, compassionate, so that students, um, can feel comfortable and relieved and that ease and willing to open up to allow for that type of communication to happen.

School vision and leadership. Interviewees mentioned that one of the unique features of the school was that school administrators were working hard to create a vision and atmosphere that were conducive to engaging marginalized youth. A staff member mentioned his enthusiasm regarding the leadership at the school:

Um, I've never worked in a building, a setting with leadership that has had a vision, that has been able to articulate that vision and to have one hundred percent buy-in from a staff like I have here at [alternative school].

\section{Discussion}

The current study illuminated one urban alternative high school's unique approach to reaching youth at risk for dropping out. This innovative approach that utilizes social-emotional learning practices in critically conscious ways adds to the existing literature on supporting and developing educational approaches for marginalized youth (e.g., Durlak et al., 2012; Merrell, 2010). Further understanding the modality of this innovative educational process answers the call for addressing the needs of youth who are at risk for dropping out of school. Previous researchers have examined students' perspectives and requests for programs to address educational and social/emotional needs (Knesting, 2008; Lagana-Riordan et al., 2011). However, this study adds to the existing literature by examining school staff members' perspectives on the implementation of a culturally relevant and critically conscious approach to 
SEL in urban alternative education. Previous work has been limited in regards to SEL in urban or alternative educational settings (Castro-Olivo \& Merrell, 2012). The overarching themes that emerged were (a) Pedagogy, (b) Relationships, (c) Community-Based Model, and (d) School Environment.

Perhaps the most salient finding, evident across all of the domains, was a focus on addressing students' social and emotional needs through culturally relevant and critically conscious education (Freire, 1970). This engagement had many different modalities, most importantly integrating it into the daily curriculum, fostering one-on-one relationships, and utilizing community partners. With these concepts in place, the participants in the current study suggested that the school environment was perceived as a welcoming and accepting space. This finding is consistent with Watts, Griffith, and Abdul-Adil (1999) suggesting that, while traditional SEL interventions are necessary and helpful, critical consciousness is also quite necessary for the success and wellness of all youth, particularly underrepresented minorities and those experiencing marginalization in the schools. These scholars argued that developing interventions to increase critical consciousness will result in both individual and community transformation. Further, Deimer and Blustein (2006) found support for the importance of critical consciousness in their study of critical consciousness of urban youth. Youth with higher levels of critical consciousness had a clearer sense of their vocational identity, were more committed to their career path, and were able to more clearly envision that their career would play in their future. Diemer and Hseih (2008) also found that critical consciousness contributed to students of color from low SES backgrounds having higher vocational aspirations. These findings suggest "critical consciousness may serve as an internal resource that assists urban adolescents in analyzing and acting to achieve desired outcomes within an environment of inequitable access to resources and racial discrimination" (Diemer \& Blustein, 2006, p. 228-229).

\section{Implications for Educators and Mental Health Professionals in Urban Schools}

The staff's perspectives about the school and SEL provide important information for school professionals working with youth at risk for academic failure in urban school settings. Based on staff perspectives, we offer three overarching recommendations for future educational practice with marginalized youth in urban schools.

\section{Integrate social-emotional learning in critically conscious and culturally relevant ways.}

Every participant mentioned innovative ways they, both individually and as a school, engaged youth and addressed social/emotional needs. Culture, when referring to culturally relevant approaches to social and emotional learning, is a term that suggests a delivery that is comprehensive and ecological, paying attention to neighborhood culture, youth popular culture, familial culture, race/ethnicity culture, and social/political culture. By utilizing these modalities, school professionals in the current study demonstrated a willingness to meet students where they were. However, SEL literature has consistently suggested a non-differentiated approach. Findings in the current study suggest that more youth are served when school professionals merge SEL, critically conscious pedagogy, and culturally relevant education to address socialemotional needs of marginalized students. 
Practically, this critically conscious approach to SEL would allow school professionals to inform students of the social and political context that may have contributed to their marginalization in the education system. Applying critically conscious principles would result in different types of SEL interventions and changes to school practices. First, students and parents could be engaged in small group discussions about the effect race, class, and gender are having on their experience in their schools. Further contextualizing the issue of violence, psychoeducation should be inserted into the curriculum that details the history of poor and marginalized persons in students' communities (e.g., Zinn, 2005). This history will allow students to reflect on their reactions to circumstances, while also allowing them to see violence as perpetuating crossgeneration oppression. Further, school professionals could intentionally dialogue with students to search for specific strengths and resources that allowed them to remain engaged in the educational system despite the myriad of oppressive factors and "isms" that stand in their way. After giving them time to talk and learn about their context and strengths, students and parents could be engaged in a process of problem-posing discussions (Freire, 1970). They would articulate the problems that emerged when they reflected on their lives and status, explore relevant strengths and resources, and discuss actions that could create a healthier environment, of which schools are but one component. This critical approach to SEL potentially allows students to grow in their emotional health and social well-being, while also creating an opportunity to determine paths to action. By giving preference to marginalized students' lived experience, calling attention to strengths, and engaging in critical dialogue, school professionals provide opportunities for systemic and individual wellness to emerge. In the current study, mental health professionals were an integral part of the educational team and the administrators of the school allowed for the allocation of mental health professionals' time and resources to meet students' SEL needs. Thus, it is imperative that school professionals have the opportunity to reach the SEL needs of youth in critically conscious ways and in order to replicate the work of professionals in this study, mental health professionals and educators will need the time and opportunity to engage youth in this manner.

\section{Invest time and energy in authentic relationships with students that foster an accepting school environment.}

The literature on students at risk for dropping out suggests that youth who experience a caring relationship with an adult are more interested in staying in school (Sánchez, Colón, \& Esparza, 2005). Unfortunately, many youth do not experience a caring relationship(s) at home or in the community. Thus, school can play a vital role in students' perceptions of being cared for by adults. Staff in the current study emphasized making a deep, non-superficial connection with individual students, with both staff member and student experiencing the vulnerability of genuine communication. Having individualized caring relationships with adults in school can foster a sense of belonging and desire to invest in school. In a practical sense, school professionals must be willing to demonstrate empathy, commit to knowing students beyond educational needs, and be genuine when engaging with them. When students experience authentic relationships with adults in school, they feel a stronger sense of belonging to their school and are more likely to have improved grades (Pittman \& Richmond, 2007), value school work (Anderman, 2003; Goodenow \& Grady, 1993), increase their effort (Goodenow \& Grady,; Sánchez et al.), persevere (Goodenow \& Grady), have achievement motivation (Ibañez, Kuperminc, Jurkovic, \& Perilla, 2004), increase their academic self-efficacy (McMahon, Wernsman, \& Rose, 2009), increase their attendance (Sánchez et al., 2005), and experience social acceptance (Freeman, Anderman, \& Jensen, 2007). 


\section{Create a school environment with an emphasis on community collaboration.}

The current study utilized interviews from several key community partners. In addition, many educators within the school who participated commented on the importance of community members engaging with youth in the schools. Previous literature on community partnerships suggests that these collaborations can help reduce substance use, alcohol use, prevent teen pregnancy, smoking, and arson (Wandersman \& Florin, 2003). Proponents of community involvement argue that schools working with marginalized youth need additional resources to successfully educate all students and that these resources are housed in students' communities (Epstein, 2010; Melaville, 1998; Waddock, 1995). There are many different types of community involvement in schools, one that was discussed by participants in the current study was student-centered activities. These student-centered activities are direct services or goods that are provided to the students from members of the community (Sanders, 2003).

Participants in the current study mentioned community educators (i.e., professionals in the community willing to share expertise) who were contracted to come to the school to teach students skills outside of the classroom, ranging from kickboxing to understanding the hip-hop music industry. These contributions provided opportunities for youth to be taught from members of the community as well as to obtain knowledge that is not usually part of the traditional classroom. Their willingness to engage the youth in the school building demonstrates that members of the community care about the students in the school. The implication of this finding for school professionals involves the increased utilization of community members in school education, programming, and SEL needs. The involvement of community members in student-centered activities provides students a sense of purpose, belonging to the community, and allows them to learn skills they may not have learned in the classroom.

\section{Limitations}

The current study examined the perspectives of staff members at an urban alternative school serving students at risk for school dropout. Given the specificity of the current study, including sample size (i.e., 14) representing one site and the methodology (i.e., CQR), it is difficult to generalize the conclusions of the study to other schools and personnel. However, the approach allowed researchers to hear the unique experiences of these staff members and given that alternative schools typically have a smaller staff the sample size was appropriate for the context. Another limitation is that the study was focused on perspectives of staff. Future research could examine youth and family perspectives on this critically conscious approach to SEL in schools. In addition, quantitative research could examine academic and SEL outcomes and inform the fields of counseling and education about the effectiveness of critically conscious SEL in urban alternative schools.

\section{Conclusion}

This study examined an innovative way to engage youth who have been educationally marginalized. Staff members at an urban alternative school emphasized that school personnel need to acknowledge and embrace the complexity of youth context when addressing social and emotional needs of youth at risk for poor outcomes. The contribution here is not only raised awareness of SEL, but also of the mechanism by which SEL can be facilitated-that is, utilizing critical consciousness. Findings suggest the important contribution of school professionals 
building relationships with youth and engaging them in conversations about their social/political context, and this can potentially generate investment in their educational experiences. Further, the impact of school professionals engaging youth in these critical conversations has the potential to initiate system change and empower the voices of youth to express their concerns regarding educational practice and marginalization by the school system in urban communities.

\section{Author Information}

Christopher D. Slaten, Counseling Psychology, Dept. of Educational, School, Counseling Psychology, University of Missouri, 306A Noyes Hall, Columbia, MO 65211-2130

Email: slatenc@missouri.edu

\section{References}

Anderman, L. H. (2003). Academic and social perceptions as predictors of change in middle school students' sense of school belonging. Journal of Experimental Education, 72, 5-22. doi: $10.1080 / 00220970309600877$

Cable, K. E., Plucker, J. A., \& Spradlin, T. E. (2009). Alternative schools: What is in a name? (Education Policy Brief No. 7.4), Bloomington, IN: Center for Evaluation and Education Policy.

Castro Olivo, S. (2010). One size does not fit all: Adapting SEL programs for use in our multicultural world. In K. W. Merrell, \& B. A. Gueldner. Social and emotional learning in the classroom: Promoting mental health and academic success. New York, NY: Guildford Publications Inc.

Castro-Olivo, S., \& Merrell, K. W. (2012). Validating cultural adaptations of a school- socialemotional learning program for use with Latino immigrant adolescents. Advances in School Mental Health Promotion, 5(2), 78-92.

Clark, M. A., \& Breman, J. C. (2009). School counselor inclusion: A collaborative model to provide academic and social-emotional support in the classroom setting. Journal of Counseling \& Development, 87, 6-11. doi: 10.1002/j.1556-6678.2009.tb00543.x 
Cox, S. (1999). An assessment of an alternative education program for at-risk delinquent youth. Journal of Research in Crime and Delinquency, 36, 323-336. doi: $10.1177 / 0022427899036003004$

Creswell, J. W. (2012). Qualitative inquiry and research design: Choosing among five approaches. Thousand Oaks, CA: SAGE Publications.

D'Angelo, F., \& Zemanick, R. (2009). The Twilight Academy: An alternative education program that works. Preventing School Failure, 53(4), 211-218. doi: 10.3200/PSFL.53.4.211-218

Diemer, M. A., \& Blustein, D. L. (2006). Critical consciousness and career development among urban youth. Journal of Vocational Behavior, 68, 220-232. doi: 10.1016/j.jvb.2005.07.001

Diemer, M.A. \& Hsieh, C. (2008). Sociopolitical development and vocational expectations among lower-SES Adolescents of Color. Career Development Quarterly, 56(3), 257-267.

Dunbar, C. (2001). From alternative school to incarceration. Qualitative Inquiry, 7(3), 158-170.

Dunbar, C. (2002). Alternative school administrators "at risk": What does it mean for children? Trotter Review, 14(1), 105-120.

Durlak, J. A., Weissberg., R. P., Dymnicki., A. B., Taylor, R. D., \& Schellinger, K. B. (2011). The impact of enhancing student's social and emotional learning: A meta-analysis of schoolbased universal interventions. Child Development, 82, 405-432. doi: 10.1111/j.14678624.2010.01564.x.

Elias, M. J., Zins, J. E., Weissberg, R. P., Frey, K. S., Greenberg, M. T., Haynes, N. M., et al. (1997). Promoting social and emotional learning: Guidelines for educators. Alexandria, VA: Association for Supervision and Curriculum Development.

Epstein, J. L. (2010). School/family/communication partnerships: Caring for the children we share. Phi Delta Kappan, 92(3), 81-96.

Flower, A., McDaniel, S. C., \& Jolivette, K. (2011). A literature review of research quality and effective practices in alternative education. Education and Treatment of Children, 4, 122.

Foley, R. M., \& Pang, L. (2006). Alternative education programs: Program and student characteristics. High School Journal, 89(3), 10-21.

Franklin, C., Skeeter, C. L., Kim, J. S., \& Tripoti, S. J. (2007). The Effectiveness of a solutionfocused public alternative school for dropout prevention and retrieval. Children and Schools, 29(3), 133-144. doi: 10.1093/cs/29.3.133

Freire, P. (1970). Pedagogy of the oppressed. New York: Herder and Herder. 
Freeman, T. M., Anderman, L. H., \& Jensen, J. M. (2007). Sense of belonging in college freshmen at the classroom and campus levels. Journal of Experimental Education, 75, 203-220. doi: 10.3200/JEXE.75.3.203-220

Geronimo, I. I. (2011). Deconstructing the marginalization of "underclass" students: Disciplinary alternative education. The Toledo Law Review, 42, 429-465.

Gonzalez, L., Stein, G., Shannonhouse, L., \& Prinstein, M. (2012). "As long as I work hard I'll be fine": Latino students' views of the path to college. Journal for Social Action in Counseling and Psychology, 4(1) 83-102.

Goodenow, C., \& Grady, K. E. (1993). The relationship of school belonging and friends' values to academic motivation among urban adolescent students. The Journal of Experimental Education, 62, 60-71. doi: 10.1080/00220973.1993.9943831

Guerin, G., \& Denti, L. (1999). Alternative education support for youth at-risk. The Clearing House, 73(2), 76-78. doi: 10.1080/00098659909600151

Gut, E., \& McGlaughlin, J. M. (2012). Alternative education's impact on office disciplinary referrals. The Clearing House, 85(6), 231-236. doi:10.1080/00098655.2012.695409

Greenfield, R., Rinaldi, C., Proctor, C. P., \& Cardarelli, A. (2010). Teachers' perceptions of a response to intervention (RTI) reform effort in an urban elementary school: A consensual qualitative analysis. Journal of Disability Policy Studies, 21, 47-63. doi: $10.1177 / 1044207310365499$

Hill C. E. (2012). Introduction to Consensual Qualitative Research. In C. E. Hill (Ed.), Consensual Qualitative Research: A practical resource for investigating social science phenomenon (pp. 3-20). Washington D.C.: American Psychological Association.

Hill, C. E., Thompson, B. J., \& Williams, E. N. (1997). A Guide to Conducting Consensual Qualitative Research. The Counseling Psychologist, 25(4), 517-572. doi: $10.1177 / 0011000097254001$

Ibañez, G. E., Kuperminc, G. P., Jurkovic, G., \& Perilla, J. (2004). Cultural attributes and adaptations linked to achievement motivation among Latino adolescents. Journal of Youth and Adolescence, 33, 559-568. doi:10.1023/B:JOYO.0000048069.22681.2c

Irby, D. (2013). Net-deepening of school discipline. Urban Review, 45(2), 197-219. doi: 10/1007/s11256-012-0217-2.

Kennedy-Lewis, B. L. (2012). What happens after students are expelled? Understanding teachers' successes and failures at one alternative middle school. Teachers College Record, 114(12), 1-38.

Kim, J., \& Taylor, K. A. (2008). Rethinking alternative education to break the cycle of educational inequality and inequity. The Journal of Educational Research, 101(4), 207219. doi: 10.3200/JOER.101.4.207-219 
Knesting, K. (2008). Students at risk for school dropout: Supporting their persistence. Preventing School Failure, 52(4), 3-10. doi: 10.3200/PSFL.52.4.3-10

Kress, J. S., \& Elias, M. J. (2006). School based social and emotional learning programs. In K. A. Renninger \& I. E. Sigel (Eds.), Handbook of child psychology: Vol. 4. Child psychology in practice (6th ed., pp. 592-618). Hoboken, NJ: John Wiley and Sons.

Lagana-Riordan, C., Aguilar, J. P., Franklin, C., Streeter, C. L., Kim, J. S., Tripodi, S. J., \& Hopson, L. (2011). At-risk students' perceptions of traditional schools and a solutionfocused public alternative school. Preventing School Failure, 55(3), 105-114. doi: $10.1080 / 10459880903472843$

Lewis, K., \& Burd-Sharps, S. (2010). The measure of America 2010-2011: Mapping risks and resilience. New York: NYU Press.

McMahon, S. D., Wernsman, J., \& Rose, D. (2009). The relation of classroom environment and school belonging to academic self-efficacy among urban fourth-and fifth-grade students. The Elementary School Journal, 109, 267-281.

Melaville, A. (1998). Learning together: The developing field of school-community initiatives. Flint, MI: Mott Foundation.

Merrell, K. W. (2009). Linking prevention science and social and emotional learning: The Oregon Resiliency Project. Psychology in the Schools, 47, 55-70. doi: 10.1002/pits.20451

National Center for Education Statistics (2011). The condition of education, 2011. Washington, D.C.: U.S. Department of Education, National Center for Education Statistics. Retrieved from http://nces.ed.gov/pubs2011/2011033.pdf

Oakes, J. (2005). Keeping track: How schools structure inequality (2nd ed.). New Haven, CT: Yale University Press.

Pittman, L. D., \& Richmond, A. (2007). Academic and psychological functioning in late adolescence: The importance of school belonging. Journal of Experimental Education, 75, 270-290. doi: 10.3200/JEXE. 75.4.270-292

Price, D., Pepper, K., \& Brocato, K. (2006). The importance of making the well-being of children in poverty a priority. Early Childhood Education Journal, 34(1), 21-28. doi: 0.1007/s10643-006-0118-7

Quinn, M. M., Poirier, J. M., Faller, S. E., Gable, R. A., \& Tonelson, S. B. (2006). An examination of school climate in effective alternative programs. Preventing School Failure, 51, 11-17. doi: 10.3200/PSFL.51.1.11-17

Raywid, M. A. (1981). The first decade of public school alternatives. Phi Delta Kappan, 62(8), 551-554. 
Raywid, M. A. (1983). Alternative schools as a model for public education. Theory into Practice, 22(3), 190-197.

Reilly, D. H., Reilly, J. L. \& West, E. L. (1982). An alternative learning school: Student results and system considerations. Journal of Instructional Psychology, 9(3), 122-132.

Reisler, R., \& Friedman, M. S. (1978). Radical misfits? How students from an alternative junior high school adapted to a conventional high school. Education Theory, 28, 75-81. doi: 10.1111/j.1741-5446.1978.tb00796.x

Ross, M. R., Powell, S. R., \& Elias, M. J. (2002). New roles for school psychologists: Addressing social and emotional learning needs of students. School Psychology Review, 31, 43-52.

Samarova, V., Shilo, G., \& Diamond, G. M. (2013). Changes in youths' perceived parental acceptance of their sexual minority status over time. Journal of Research on Adolescence, Advance online publication. doi: 10.1111/jora.12071

Sánchez, B., Colón, Y., \& Esparza, P. (2005). The role of school belonging and gender in the academic adjustment of Latino adolescents. Journal of Youth and Adolescence, 34, 619628. doi: 10.1007/s10964-005-8950-4

Sanders, M. G. (2003). Community involvement in schools from concept to practice. Education and Urban Society, 35(2), 161-180. doi: 10.1177/0013124502239390

Sinha, J. W. (2007). Youth at risk for truancy detour into a faith-based education program: Their perceptions of the program and its impact. Research on Social Work Practice, 17(2), 246-257. doi: 10.1177/1049731506296944

Thompson, B. J., Vivino, B. L., \& Hill, C. E. (2012). Coding the data: Domains and core ideas. In C. E. Hill (Ed.), Consensual Qualitative Research: A practical resource for investigating social science phenomenon (p. 103-116). Washington D.C.: American Psychological Association.

Tolan, P.H., \& Dodge, K. A. (2005). Children's mental health as a primary care and concern: A system for comprehensive support and service. The American Psychologist, 60(6), 601614.

Waddock, S. A. (1995). Not by schools alone: Sharing responsibility for America's education reform. Westport, CT: Praeger.

Wandersman, A. \& Florin, P. (2003). Community interventions and effective prevention. American Psychologist, 58, 441-448.

Watts, R. J., Griffith, D. M., \& Abdul-Adil, J. (1999). Sociopolitical development as an antidote for oppression-theory and action. Journal of Community Psychology, 27(2), 255-271. doi: $10.1023 / A: 1022839818873$ 
Weissburg, R. P. (2000). Improving the lives of millions of school children. The American Psychologist, 55(11), 1360-1373.

Zinn, H. (2005). A people's history of the United States. New York, NY: Harper Perennial.

Table 1

Summary of Domains, Categories, and Frequencies

\begin{tabular}{lll}
\hline Domain Category & Frequency Label
\end{tabular}

\section{Pedagogy}

Social-emotional learning

General (14)

Personalized Learning

General (14)

Cultural Relevance to Youth

Typical (9)

Social/Political Content

Typical (8)

Black/African Centered Content

Variant (6)

\section{Relationships}

Being vulnerable and relatable to students

Typical (9)

Encouraging students

Variant (6)

Knowing students beyond school

Variant (6)

Relational needs as a pre-requisite to learning

Variant (5)

\section{Community-based Model}

Opportunity for Emotional Healing

Typical (14)

Community as a resource

Typical (9)

Professional Development

Variant (2)

\section{School Environment}

Climate of respect

Typical (13)

Emotional Intelligence

Typical (12)

School vision and leadership

Typical (7) 


\section{Appendix A}

\section{Interview Protocol}

1. Could you please describe your role at the School?

a. For staff: How does this compare to other places of employment?

b. Why did you choose to be a part of this school?

2. Can you describe your experience being part of this High School?

3. Alternative schools often have the opportunity to incorporate new and innovative methods in the way in which they educate students. In what way(s), if any, has this school utilized non-traditional methods to educate students?

4. In what ways does the school help marginalized youth overcome challenges they face?

5. What, if any, are the components of the school that are unique compared to other alternative schools?

6. Oftentimes students can become disengaged academically when they do not feel as though they belong at their school. How has the school addressed school culture and attempted to engage students? 